\title{
El Seguro Marítimo $y$ el riesgo de guerra
}

\author{
Por Xavior Kiefor-Marchand
}

La costumbre quiere que, desde mucho tiempo, se excluyan los riesgos de guerra de los seguros ordinarios.

Sobre esta cuestión, las diferentes legislaciones han adoptado dos sistemas distintos:

Según el primero, los riesgos de guerra están comprendidos entre los riesgos a cargo de los aseguradores pero, en la práctica, las pólizas los excluyen de los riesgos ordinarios de la navegación. Esto sucede, entre otros países: en Alemania, Argentina, Canadá, España, Estados Unidos, Francia, Gran Bretaña y Holanda.l Es también el sistema adoptado por el Código de Comercio del Perú (art. 769, inciso 10 ).

Otras legislaciones han preferido - lo que es más lógico sancionar lo que sucede en la práctica. Según ellas, los aseguradores, salvo convenio expreso, quedan exceptuados del pago de la indemnización en caso de riesgo de guerra. Han adoptado este sistema: Bélgica, Italia, Marruecos y Portugal, entre otros. En Francia, se presentaron dos proyectos en este sentido, en 1887 y en 1926, pero ambos no pasaron de proyectos. Este sistema tiene, evidentemente, mayores ventajas, ya que no vale la pena fijar normas que, en la práctica, no se cumplen por acuerdo entre las partes.

El seguro marítimo contra los riesgos de guerra ha adquirido sobre toda gran importancia desde la primera guerra mundial de 1914-1918. Los peligros para la navegación resultaron entonces considerables con la aparición de nuevos elementos de destrucción, desconocidos en las guerras anteriores, principalmente el submarino que tantas pérdidas ocasionó a las marinas mercantes. Esta importancia, lejos de decaer, ha aumentado en el actual conflicto, llegando 
los aseguradores a cobrar premios que han pasado del $30 \%$ para los buques que navegaban en zonas peligrosas.

Ahora bien, al iniciarse la guerra de 1914- 1918, los Estados, principalmente los beligerantes, han tenido que adoptar medidas especiales para proteger su marina mercante en serio peligro. Las disposiciones así tomadas están contenidas en decretos y leyes que han sido posteriormente adaptadas a las nuevas circunstancias. como lo aconsejaba la experiencia anterior, al iniciarse el actual conflicto mundial.

Vamos a examinar a continuación las disposiciones que contiene el Código de Comercio Francés de 1808, vigente, y la nueva legislación que, en materia de riesgo de guerra, fué adoptada por Francia como consecuencia de los dos conflictos en los cuales tuvo que intervenir este país.

El artículo 350 del Código de Comercio.-Según el artículo 350 del Código de Comercio, todos los riesgos de mar están a cargo del asegurador. Estos riesgos, que enumera detalladamente, pueden clasificarse en tres categorías:

a) -ricsgos de mar propliamente dichos: tempestad, naufragio, varadura, abordaje, cambios obligados de ruta, de viaje, o de buque, echazón o toda avería común.

b) -incendio a bordo: (el asegurador no es, sin embargo, responsable cuando el incendio tiene por causa un vicio propio de la cosa o una falta del capitán).

c) -riesgos de guerra: captura, saqueo, detención por orden de una potencia extranjera, declaración de guerra o represalias.

En 1840, las pólizas francesas excluyeron el riesgo de guerra de los riesgos a cargo de los aseguradores. Este riesgo fué, desde entonces, objeto de condiciones especiales que figuraban en anexos a las pólizas (premios suplementarios, etc.).

Periodo de 1914-1918.-Es solamente en 1914 que, en Francia, se preocuparon verdaderamente de reglamentar el seguro marítimo de riesgo de guerra. Ante el peligro que amenazaba entonces a la navegación, era preciso adoptar medidas inmediatas.

Por un decreto del 11 de agosto de 1914 (nueve días después 
de declarada la guerra), el Gobierno creó una "Comisión Ejecutiva de las Compras y Transportes Marítimos, efectuados para asegurar la alimentación nacional". Esta Comisión, que debía funcionar en el Ministerio de Hacienda, se componía de representantes de los Ministerios de Guerra y Marina, funcionarios del Ministerio de Hacienda, un Catedrático de Derecho Comercial y varios dirigentes de Compañías de Seguros.

Dos dias después y como una consecuencia del anterior decreto, el Gobierno Francés, resolvió con fecha 13 de agosto de 1914, que "durante las hostilidades, el Estado Francés podria garantizar contra los riesgos de guerra, tanto a los buques como a sus cargamentos" (art. 1).

En cuanto a los buques, la garantía del Estado solo se aplicaba a los buques franceses, inscritos en un puerto francés, siempre que estuvieren asegurados contra los riesgos ordinarios de la navegación hasta un $25 \%$ de su valor (art. $2^{\circ}$ ). Sin embargo, la garantía no podía sobrepasar el $80 \%$ del valor del buque (art $3^{\circ}$ ). A cambio de esta garantía, el Estado cobraba un premio que no podía exceder del $5 \%$ de la suma garantizada (art. $4^{\circ}$ ). Quedaba, naturalmente, convenido que el buque debía someterse a las instrucciones de las autoridades francesas o aliadas en cuanto a la ruta que tenía que seguir (art. 5). Las sumas adeudadas por el Estado por concepto de esta garantía debían pagarse a los seis meses de la presentación de los respectivos comprobantes (art. 7).

Tratándose de las mercaderias, el decreto hacia una distinción entre la importación y la exportación. La garantía del Fstado cubría el valor total de las mercaderías importadas en buques franceses, aliados o neutrales, pero solamente las exportadas en buques franceses (art. 8). Esta última disposición fué modificada por un decreto del 10 de Octubrẹ de 1914 que extendió la garantía del Estado a las mercaderías exportadas tanto en buques franceses como aliados y neutrales. El premio fijado para las mercaderías era el mismo que para los buques, es decir del $5 \%$, como máximo, del valor de la suma asegurada.

El decreto del 13 de agosto de 1914 indicaba los casos en los cuales los armadores estarian exentos de responsabilidad y podrían reclamar el pago de la indemnización correspondiente. Un decreto posterior (12 de noviembre de 1914) anulaba estas disposiciones, bastante liberales, resolviendo que "si el buque sale del puerto contrariamente a las instrucciones recibidas de las autoridades francesas o aliadas o no observa dichas instrucciones durante el viaje, el Estado quedará, por su propia voluntad, desligado de toda obligación, quedando a su favor la mitad del premio pactado". (art. 2). 
Todas las disposiciones de éstos decretos fueron reunidas en una ley que lleva la fecha del 10 de abril de 1915 y que reproduce, por lo tanto, el decreto del 13 de agosto de 1914 con sus modificaciones estáblecidas por los decretos del 10 de octubre y 12 de noviembre de 1914.

En 1917, en vista del progreso considerable de la guerra submarina y de los estragos que producía, el Gobierno, por un decreto del 25 de enero, suspendió el máximo del $5 \%$ que había fijado como premio para el seguro de riesgo de guerra.

El 19 de abril de 1917, se promulgó una ley de mucha importancia. Esta establecía, en efecto, el seguro obligatorio por el Estaclo, contra el riesgo de guerra, de todos los buques franceses de 500 y más toneladas, dejando como facultativo dicho seguro para los buques franceses de menos de 500 toneladas y para. los buques aliados o neutrales fletados por franceses. A cambio de la indicada garantía el Estado cobraba un premio mensual que variaba según la categoría del buque y el viaje por realizar. Si el buque se perdía totalmente, el Estado pagaba el $75 \%$ de la suma asegurada. El saldo solo lo pagaba cuando la suma entregada, es decir el $75 \%$, había sido empleada en la adquisición o construcción de otro buque, con la aprobación previa del Ministerio de Marina.

Habiendo el Estado procedido, por decreto del 15 de febrero de 1918, a la requisición de todos los buques mercantes franceses hasta el fin de las hostilidades, se resolvió que todas las cuestiones relacionadas con esta requisa y las indemnizaciones correspondientes serían objeto de convenios especiales entre el Estado y los armadores.

Firmado el armisticio el 11 de noviembre de 1918, un decreto del 15 del mismo mes redujo en un $75 \%$ el valor de los premios que se cobraban hasta entonces por concepto de seguros contra los riesgos de guerra.

Tal era la legislación franceses adoptada con motivo de la primera guerra mundial de 1914-1918.

Periodo de 1938-1942.-Desde 1938, todo hacía prever que un nuevo conflicto se avecinaba rápidamente.

El Gobierno Francés promulgó el 11 de julio de 1938 una ley sobre "la organización general de la nación en tiempo de guerra". Esta ley, que comprende 66 artículos, declara, en el art. 22, que el Gobierno está facultado para proceder a la requisa de los buques conforme al art. 35 de la ley del 3 de julio de 1877, nodificada por la del 21 de enero de 1935. Agrega que esta medida efectuada en la sede de una Compañía de Navegación se extendería ipso-facto a todos los buques de la misma, aún a los que se encontrasen en alta mar o en aguas extranjeras. 
En la práctica, esta requisa no fué general. Cuando estalló la guerra, en Setiembre de 1939, las principales Compañias tenian convenios, aún vigentes, con el Gobierno. Este último permitió a las Compañias que escogieran entre el mantenimiento de dichos convenios $y$ la requisa de sus buques para el tiempo que durase la guerra. Casi todas optaron por la primera solución. Naturalmente, de acuerdo con las mismas convenciones, el Estado estaba autorizado a efectuar. un control más directo sobre las diferentes líneas, pero no intervino en la administración interior de las compañías. Los acuerdos tomados permitían, igualmente, a la Dirección de Transportes Maritimos posesionarse de determinados buques. En este caso, la compañía solo tenía obligación de mantener al buque en buen estado de navegabilidad y de asegurarle su completa dotación de personal y material. En cuanto a los seguros, las pólizas debían en este caso, ser endosadas a favor del Estado, mientras los buques seguian fletados por éste.

Un decreto del 6 de mayo de 1939 reglamentó los seguros marítimos en tiempos de guerra.

Este decreto establece que el seguro de los riesgos de guerra por el Fistado es obligatorio para los buques de bandera francesa o registrados en un puerto del Imperio colonial Francés, a partir de 500 toneladas brutas. Es solo opcional para los buques de menor tonelaje.

Al perderse totalmente un barco asegurado por el Estado, éste, por medio de la "Comisión para el Seguro de Riesgos Marítimos de Guerra”, pagará el $50 \%$ del valor asegurado. El saldo sólo se entregará si el producto del seguro es empleado en la adquisición de otro buque de idénticas características. Como se recordará, el decreto del 19 de abril de 1917 autorizaba el pago, en estas condiciones, del $75 \%$ del valor asegurado.

El decreto del 6 de mayo de 1939 permite, igualmente, al Estado asegurar contra riesgos de guerra los cargamentos llevados en buques franceses, aliados o neutrales. El monto asegurado contra riesgos de guerra podía ser igual al fijado para el seguro maritimo ordinario.

El decreto del 6 de mayo de 1939 fué modificado por los decretos del $1^{\circ}$ de setiembre de 1939 (en cuanto a la forma de llevarse las cuentas relacionadas con los seguros de guerra), y del 30 de Julio de 1941. Este último confirmaba, en parte, todas las disposiciones del anterior, según el cual, en caso de pérdida total de un buque francés, asegurado por el Estado, éste solo pagaría el $50 \%$ del valor asegurado, entregando el saldo, es decir el $50 \%$ restante, en caso de que la suma pagada hubiera sido empleada en la adquisición o construcción de otro buque que reuniese condiciones simlares a las del buque perdido. Pero, agregaba que las características y demás con- 
diciones del barco que se proyectaba adquirir o construir debían ser sometidas a consideración del Ministerio de Marina, para su debida aprobación, ejecución y control.

Como se puede observar, las medidas adoptadas por el Estådo Francés en materia de seguro marítimo son el fruto de la experiencia adquirida en dos guerras mundiales.

El fin principal de estas medidas consiste en mantener el tonelaje de la flota mercante del país, en serio peligro de desaparecer debido a los medios de destrucción empleados en las guerras modernas.

Para lograrlo, el Estado establece el seguro obligatorio de los buques mercantes franceses en tiempos de guerra. Pero, como pocas Compañías podrían hacer frente a los pagos casi fabulosos que exigirían ciertos siniestros, el Estado se sustituye a estas y se transforma en asegurador. $Y$, por fin, exige como condición esencial para que se verifique el pago total de la indemnización que esta sea empleada en la adquisición o construcción de otro buque, según las condiciones que fijará oportunamente el Ministerio de Marina Francés.

Las medidas tomadas por el Gobierno Francés, y las garantías de que se ha rodeado para lograr su fin han dado excelentes resultados en la práctica.

Por estas razones, nos ha parecido interesante enumerar las disposiciones adoptadas por Francia en cuanto al riesgo de guerra. Además constituyen un ejemplo de la moderna legislación relacionada con esta parte del Derecho Comercial Marítimo. 